\title{
COMUNICAÇÃO
}

\section{ALTERAÇÕES NOS TEORES DE MACRONUTRIENTES EM PLANTAS DE FEIJOEIRO INFECTADAS POR Curtobacterium flaccumfaciens PV.flaccumfaciens}

\begin{abstract}
ANTONIO CARLOS MARINGONI ${ }^{1}$
RESUMO - Com o presente trabalho objetivou-se avaliar os teores de nitrogênio, fósforo, potássio, cálcio, magnésio e enxofre na massa de matéria seca da parte aérea de plantas de feijoeiro das cultivares IAC Carioca Aruã, IAC Carioca Pyatã, IAC Carioca Akytã (resistentes à murcha-de-Curtobacterium), Pérola e IAC Carioca (suscetíveis à murcha-de-Curtobacterium) inoculadas ou não com um isolado de Curtobacterium flaccumfaciens

pv. flaccumfaciens. Foi observado que plantas das diferentes cultivares de feijoeiro infectadas por C. flaccumfaciens pv. flaccumfaciens apresentam reduções na massa de matéria seca da parte aérea e nos teores desses macronutrientes. As reduções dos teores de nitrogênio, fósforo, potássio, cálcio e magnésio foram menores nas cultivares resistentes do que nas cultivares suscetíveis à murcha-de-Curtobacterium.
\end{abstract}

TERMOS PARA INDEXAÇÃO: Phaseolus vulgaris, doença, conteúdo de nutrientes, murcha-de-Curtobacterium.

\section{MACRONUTRIENTS CONTENT ALTERATIONS IN DRY BEAN PLANTS INFECTED BY Curtobacterium faccumfaciens PV.flaccumfaciens}

\begin{abstract}
The objective of this research was to evaluate nitrogen, phosforus, potassium, calcium, magnesium, and sulfur contents on shoot dry matter of bean plants cultivars IAC Carioca Aruã, IAC Carioca Pyatã, IAC Carioca Akytã (resistant to the bacterial wilt), IAC Carioca, and Pérola (susceptible to the bacterial wilt) inoculated or not with one isolate of
\end{abstract}

Curtobacterium flaccumfaciens pv. flaccumfaciens. It was observed that all cultivars infected by $C$. flaccumfaciens pv. flaccumfaciens showed reduction of shoot dry matter and macronutrient contents. However, resistant cultivars had a lower reduction of nitrogen, phosforus, potassium, calcium, and magnesium contents than bacterial wilt suceptible cultivars.

INDEX TERMS: Phaseolus vulgaris, disease, nutrient content, bacterial wilt.

Poucos trabalhos relataram as alterações nos teores de macro ou de micronutrientes em tecidos de plantas doentes. Tem-se conhecimento do efeito de alguns nutrientes aplicados na adubação sobre a suscetibilidade de plantas às doenças. A aplicação de nitrogênio na forma de uréia em altas concentrações predispôs plantas de arroz à brusone, causada por Magnaporthe grisea (Buir et al., 1959). Com relação ao fósforo, a deficiência desse elemento aumentou a severidade da podridão radicular em soja, causada por Rhizoctonia solani (Castano \& Kernkamp, 1956). A severidade do cancro da haste da soja, causada por Diaporthe phaseolorum f. sp. meridionalis foi reduzida com a adubação potássica utilizada (Mascarenhas et al., 1997). Em alguns patossistemas, como Erwinia carotovoara subsp. carotovora e tubérculos de batata, têm-se evidenciado que o aumento no teor de cálcio no tubérculo elevou a resistência à podridão mole (McGuire \& Kelman, 1984).

Alterações nos teores de macro e ou de micronutrientes em plantas doentes foram observadas em algumas situações. Plantas de Pseudotuga menziessi, com sistema radicular infectado pelo nematóide Xyphinema bakeri, possuíam menores teores de nitrogênio, fósforo,

1. Faculdade de Ciências Agronômicas - UNESP, Departamento de Produção Vegetal, Caixa Postal 237, 18603970 - Botucatu, SP, maringoni@fca.unesp.br 
potássio e magnésio do que plantas não infectadas ( $\mathrm{Su}$ theland \& Sluggett, 1973). Tanabe et al. (1977) observaram em folhas de Pyrus serotina com sintomas da doença denominada "yuzuhada" menores teores de nitrogênio, cálcio e boro e teores mais elevados de potássio e magnésio do que em folhas sadias. Das (1994) constatou redução no teor de clorofila, nitrogênio, fósforo e potássio em folhas de arroz infectadas por Gerlachia oryzae. Folhas de Lathyrus sativus colonizadas por Peronospora lathyri-palustris não apresentaram alterações nos teores de fósforo, potássio e cálcio, mas sim menores teores de nitrogênio e ferro, quando comparadas com folhas sadias (Prasad et al., 1997). A baixa severidade da brusone, em panículas de arroz, foi associada a altas concentrações de potássio e zinco e baixas concentrações de nitrogênio, fósforo e magnésio (Filippi \& Prabhu, 1998). Em folhas de plantas de laranjeira com sintomas de queda prematura de frutos, Goes \& Creste (2000) observaram maiores teores de nitrogênio e menores teores de cálcio, magnésio e zinco, quando comparados com os teores desses elementos em folhas sadias.

A murcha-de-Curtobacterium do feijoeiro, causada por Curtobacterium flaccumfaciens pv. Flaccumfaciens, é uma doença que foi constatada há poucos anos no Brasil (Maringoni \& Rosa, 1997) e tem ocorrido com muita freqüência em culturas conduzidas no Vale do Paranapanema, no Estado de São Paulo (Maringoni, 2002). Trabalhos desenvolvidos por Maringoni (2002) evidenciaram resistência nas cultivares de feijoeiro IAC Carioca Aruã, IAC Carioca Pyatã e IAC Carioca Akytã a essa doença e também menor redução da matéria seca da parte aérea dessas cultivares, quando comparadas com cultivares suscetíveis. Em razão de informações de alterações nos teores de nutrientes em plantas doentes, em vários patossistemas, com o presente trabalho objetivou-se avaliar os teores de nitrogênio, fósforo, potássio, cálcio, magnésio e enxofre na massa de matéria seca de tecidos da parte aérea de plantas de feijoeiro 'IAC Carioca Aruã', 'IAC Carioca Pyatã', 'IAC Carioca Akytã', '’Pérola' e 'IAC Carioca', inoculadas ou não com um isolado de C. flaccumfaciens pv. flaccumfaciens, submetidas às condições de casa-de-vegetação.

Dois ensaios foram conduzidos simultaneamente com essas cultivares de feijoeiro, com ou sem inoculação das plantas. As plantas foram obtidas em vasos de 8 L de capacidade, contendo substrato composto da mistura de terra de barranco, areia grossa lavada e esterco de curral curtido, na proporção de 1:1:1, acrescido de $0,6 \mathrm{Kg}$ de sulfato de amônio, $1,7 \mathrm{Kg}$ de superfosfato simples, 0,6 Kg de cloreto de potássio e $0,8 \mathrm{Kg}$ de calcáreo dolomítico, para cada $\mathrm{m}^{3}$ da mistura. Elas foram mantidas sob condições de casa-de-vegetação, com controle parcial de temperatura (amplitude de 25 a $32^{\circ} \mathrm{C}$ ) e umidade. Irrigações diárias e pulverizações semanais com defensivos registrados para a cultura foram realizadas nas plantas. Três plantas foram mantidas em cada vaso, e aos nove dias após a emergência, efetuaram-se as inoculações mediante duas punções no caule de cada planta, entre as folhas cotiledonares e as folhas primárias, com uma agulha entomológica previamente molhada em colônias bacterianas do isolado Feij-2625, com $96 \mathrm{~h}$ de idade, desenvolvidas em meio de cultura nutriente-sacarose-ágar, a $28^{\circ} \mathrm{C}$ (Maringoni, 2002). No ensaio sem inoculação, as plantas de feijoeiro receberam água destilada em vez de inóculo bacteriano. Cada parcela foi constituída de um vaso e repetida cinco vezes. O delineamento experimental utilizado foi o de blocos ao acaso.

Aos trinta e um dias após a inoculação, procedeu-se à coleta da parte aérea das plantas de cada parcela, visando a determinar a massa de matéria seca, em gramas. Para a determinação da massa de matéria seca, as plantas foram transferidas para sacos de papel e mantidas em estufa de circulação de ar forçada, à temperatura de $60^{\circ} \mathrm{C}$, durante um período aproximado de $72 \mathrm{~h}$, até que o peso se mantivesse constante, sendo, em seguida, moídas em moinho tipo "Wiley".

As análises químicas dos macronutrientes foram realizadas conforme Malavolta et al. (1989). Posteriormente, os resultados obtidos das análise químicas foram transformados em gramas por planta e calculadas as reduções percentuais dos macronutrientes nas plantas inoculadas.

Para todas as cultivares de feijoeiro, foram observados menores concentrações de nitrogênio, fósforo, potássio, cálcio, magnésio e enxofre nos tecidos das plantas inoculadas (Figuras 1 a 5). As reduções nas concentrações desses macronutrientes variaram entre as cultivares (Tabela 1). Para as cultivares com maiores níveis de resistência à murcha-de-Curtobacterium, principalmente a IAC Carioca Aruã e a IAC Carioca Pyatã, observaram-se menores reduções percentuais de nitrogênio, fósforo, potássio, cálcio e magnésio, quando comparadas com as cultivares suscetíveis IAC Carioca e Pérola. A variação na redução do enxofre não foi tão marcante entre as cultivares de feijoeiro (Tabela 1 ). 


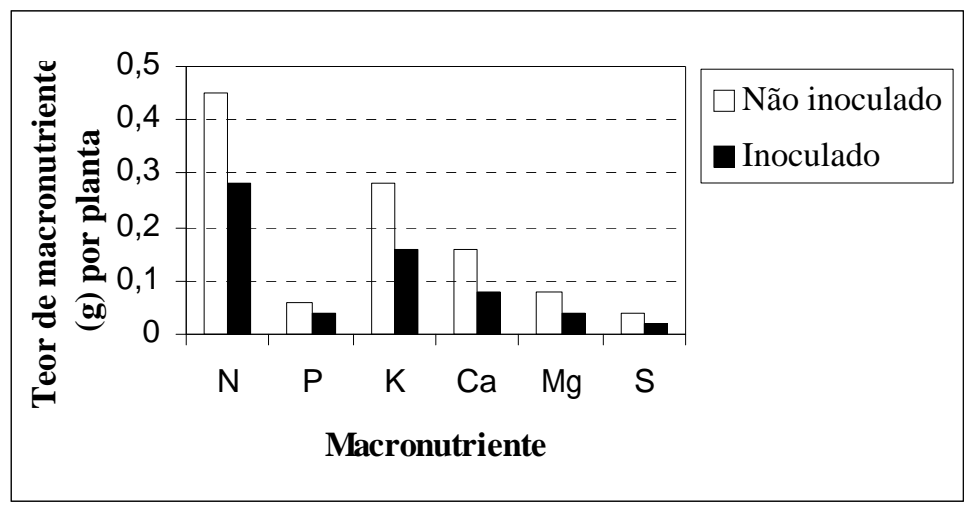

FIGURA 1 - Avaliação dos teores de macronutrientes na massa de matéria seca da parte aérea de planta de feijoeiro cultivar IAC Carioca Akytã, inoculada ou não com Curtobacterium flaccumfaciens pv. flaccumfaciens, aos 31 dias após a inoculação.

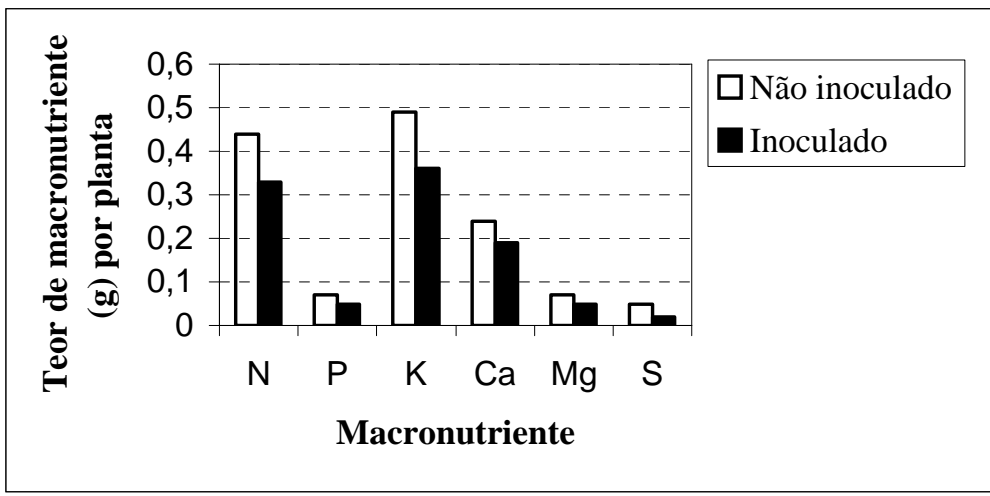

FIGURA 2 - Avaliação dos teores de macronutrientes na massa de matéria seca da parte aérea de planta de feijoeiro cultivar IAC Carioca Aruã, inoculada ou não com Curtobacterium flaccumfaciens pv. flaccumfaciens, aos 31 dias após a inoculação.

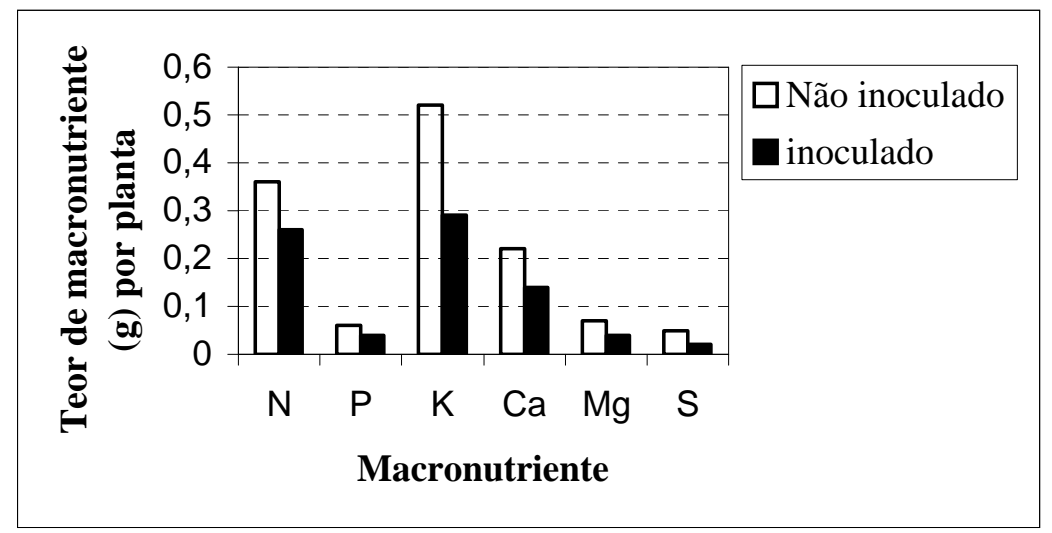

FIGURA 3 - Avaliação dos teores de macronutrientes na massa de matéria seca da parte aérea de planta de feijoeiro cultivar IAC Carioca Pyatã, inoculada ou não com Curtobacterium flaccumfaciens pv. flaccumfaciens, aos 31 dias após a inoculação. 


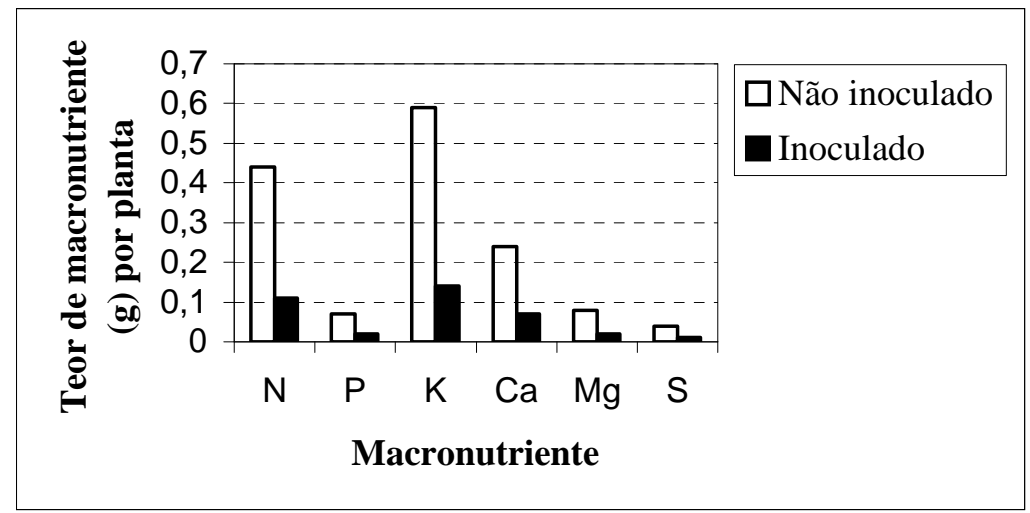

FIGURA 4 - Avaliação dos teores de macronutrientes na massa de matéria seca da parte aérea de planta de feijoeiro cultivar Pérola, inoculada ou não com Curtobacterium flaccumfaciens pv. flaccumfaciens, aos 31 dias após a inoculação.

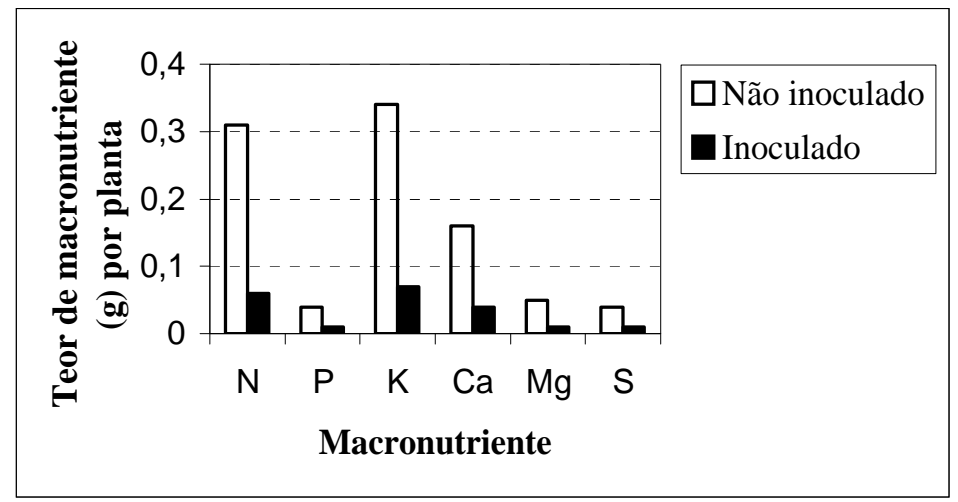

FIGURA 5 - Avaliação dos teores de macronutrientes na massa de matéria seca da parte aérea de planta de feijoeiro cultivar IAC Carioca, inoculada ou não com Curtobacterium flaccumfaciens pv. flaccumfaciens, aos 31 dias após a inoculação.

TABELA 1 - Massa de matéria seca da parte aérea e redução média, em porcentagem, nos teores de macronutrientes de plantas de cinco cultivares de feijoeiro infectadas por Curtobacterium flaccumfaciens pv. flaccumfaciens, aos 31 dias após a inoculação.

\begin{tabular}{|c|c|c|c|c|c|c|c|c|}
\hline \multirow{2}{*}{ Cultivar } & \multicolumn{2}{|c|}{$\begin{array}{l}\text { Massa da matéria } \\
\text { seca }(\mathrm{g})\end{array}$} & \multicolumn{6}{|c|}{ Redução de macronutriente na planta infectada (\%) } \\
\hline & $\begin{array}{l}\text { Planta } \\
\text { sadia }\end{array}$ & $\begin{array}{c}\text { Planta } \\
\text { infectada }\end{array}$ & $\mathbf{N}$ & $\mathbf{P}$ & $\mathbf{K}$ & $\mathbf{C a}$ & Mg & $\mathbf{S}$ \\
\hline IAC Carioca Akytã & 15,70 & 7,74 & $44,75 b^{1}$ & $50,25 \mathrm{bc}$ & $54,25 \mathrm{ab}$ & $48,25 \mathrm{ab}$ & $53,75 \mathrm{ab}$ & $60,00 \mathrm{ab}$ \\
\hline IAC Carioca Aruã & 16,54 & 9,25 & $27,25 \mathrm{~b}$ & $34,50 \mathrm{c}$ & $32,00 \mathrm{~b}$ & $26,25 \mathrm{~b}$ & $32,50 \mathrm{~b}$ & $60,00 \mathrm{ab}$ \\
\hline IAC Carioca Pyatã & 14,69 & 7,13 & $24,60 \mathrm{~b}$ & $37,40 \mathrm{c}$ & $42,60 \mathrm{~b}$ & $33,60 \mathrm{~b}$ & $42,40 \mathrm{~b}$ & $57,80 \mathrm{~b}$ \\
\hline Pérola & 16,57 & 3,19 & $73,80 \mathrm{a}$ & $73,40 \mathrm{ab}$ & $75,20 \mathrm{a}$ & $69,60 \mathrm{a}$ & $69,40 \mathrm{a}$ & $72,40 \mathrm{ab}$ \\
\hline IAC Carioca & 9,77 & 3,01 & $77,00 \mathrm{a}$ & $75,20 \mathrm{a}$ & $76,40 \mathrm{a}$ & $72,80 \mathrm{a}$ & $72,00 \mathrm{a}$ & $80,20 \mathrm{a}$ \\
\hline
\end{tabular}

${ }^{1}$ Médias seguidas de mesma letra na coluna não diferem entre si, pelo teste de Tukey ,a $5 \%$ de probabilidade.

Ciênc. agrotec., Lavras. V.27, n.1, p.217-222, jan./fev., 2003 
As reduções nos teores dos macronutrientes na massa de matéria seca da parte aérea de plantas de feijoeiros colonizadas por $C$. flaccumfaciens pv. flaccumfaciens estão relacionadas com o desenvolvimento das plantas (Tabela 1), além das alterações fisiológicas provocadas pela doença. Segundo Maringoni (2002), redução de $50,7 \%, 44,1 \%, 48,5 \%, 80,7 \%$ e $69,2 \%$ na massa de matéria seca da parte aérea de plantas de feijoeiro, respectivamente das cultivares IAC Carioca Akytã, IAC Carioca Aruã, IAC Carioca Pyatã, IAC Carioca e Pérola, foi observada em conseqüência da infecção de C. flaccumfaciens pv. flaccumfaciens. A redução no desenvolvimento das plantas infectadas fez com que houvesse menor acúmulo de macronutrientes na parte aéra.

Embora não haja padrões de alterações nos teores de macronutrientes em plantas doentes, pois isso depende da planta hospedeira e do patógeno envolvido, as reduções nos teores de nitrogênio em feijoeiros infectados por C. flaccumfaciens pv. flaccumfaciensf estão de acordo com aquelas descritas por Sutheland \& Sluggett (1973), Tanabe et al. (1997), Das (1994) e Prasad et al (1997). Os resultados obtidos para fósforo e para o potássio concordam com aqueles descritos por Sutheland \& Sluggett (1973) e Das (1994). Já para o cálcio, os resultados aqui relatados para as cultivares de feijoeiro vão de encontro àqueles observados por Tanabe et al. (1997) e Goes \& Creste (2000), e os de magnésio com aqueles de Sutheland \& Sluggett (1973) e Goes \& Creste (2000), nos diferentes patossistemas avaliados por esses autores.

Conclui-se que a parte aérea de plantas de feijoeiro infectadas por C. flaccumfaciens pv. flaccumfaciens apresentaram reduções de macronutrientes, principalmente nos de nitrogênio, fósforo, potássio, cálcio e magnésio, sendo mais acentuadas nas cultivares suscetíveis do que nas resistentes à murcha-deCurtobacterium.

\section{REFERÊNCIAS BIBLIOGRÁFICAS}

BUIR, R.; PAUZER, J.; TULLIS, E. C. The interelationship of nitrogem and other factors afeting the blast disease of rice caused by Pyricularia oryzae. Plant Disease Reporter, Saint Paul, v. 43, p. 477-482, 1959.

CASTANO, J. J.; KERNKAMP, M. F. The influence or certain plant nutrients on infection of soybeans by Rhizoctonia solani. Phytopathology, Saint Paul, v. 46, p. 326-328, 1956.
DAS, S. R. Chorophyll content and mineral composition of leaf scald infected rice leaves. Plant Disease Research, [S.1.], v. 9, p. 207-208, 1994.

FILIPPI, M. C.; PRABHU, A. S. Relationship between panicle blast severity and mineral content of plant tissue in upland rice. Journal of Plant Nutrition, Monticello, v. 21 , p. $1577-1587,1998$.

GOES, A.; CRESTE, J. E. Uso do sistema integrado de diagnose e recomendação (DRIS) na avaliação de folhas de plantas cítricas com sintomas de queda prematura de frutos. Summa Phytopathologica, Jaboticabal, v. 26, p. 237-240, 2000.

MALAVOLTA, E.; VITTI, G. C.; OLIVEIRA, S. A. Avaliação do estado nutricional das plantas. Piracicaba: Associação Brasileira para a Pesquisa da Potassa e do Fosfato, 1989. 201 p.

MARINGONI, A. C.; ROSA, E. F. Ocorrência de Curtobacterium flaccumfaciens pv. flaccumfaciens em feijoeiro no Estado de São Paulo. Summa Phytopathologica, Jaboticabal, v. 23, p. 160-162, 1997.

MARINGONI, A. C. Comportamento de cultivares de feijoeiro comum à murcha-de-curtobacterium. Fitopatologia Brasileira, Fortaleza, v. 27, p. 157-162, 2002.

MASCARENHAS, H. A. A.; ITO, M. F.; TANAKA, R. T.; AMBROSINO, G. M. B.; MURAOKA, T. Efeito da adubação potássica no cancro da haste da soja. Summa Phytopathologica, Jabotibal, v. 23, p. 217221, 1997.

MCGUIRE, R. G.; KELMAN, A. Reduced severity or Erwinia soft rot in potato tuber with increase calcium content. Phytopathology, Saint Paul, v. 74, p. 12501256, 1984.

PRASAD, B. K.; SHAMBHU, D.; SINHA, N. P.; SINGH, S. P.; KUNAR, S.; PRASAD, R. L.; DAYAL, S. Change in mineral content in Lathyrus sativus infected with Peronospora lathyri-palustris. Indian Phytopathology, New Delhi, v. 50, p. 65-67, 1997.

SUTHELAND, J. R., SLUGGETT, L. J. Corky root disease of douglas fir: relation of Xyphinema bakei nematods to symptons severity, and observation of seedling tissue and soil nutrients. Canadian Journal of Foresty Research, Ottawa, v. 3, p. 299-303, 1973. 
TANABE, K.; HAYASHI, S.; HIRATA, N.; SETO, N. nutrient content and occurrence of the disorder. Studies on yuzuka disorder of nijisseiki pear fruit Journal of the Japanese Society for Horticultural (Pyrus serotina). IV relationship between mineral Science, Sakyo-Ku, v. 45, p. 335-341, 1977. 